\title{
Management of Product Configuration Conflicts to Increase the Sustainability of Mass Customization
}

\author{
Vladimir Modrak * $\mathbb{D}$ and Zuzana Soltysova \\ Faculty of Manufacturing Technologies, Technical University of Kosice, Bayerova 1, 08001 Presov, Slovakia; \\ zuzana.soltysova@tuke.sk \\ * Correspondence: vladimir.modrak@tuke.sk; Tel.: +421-55-602-6449
}

Received: 30 March 2020; Accepted: 28 April 2020; Published: 29 April 2020

\begin{abstract}
An important role in product variety management is finding an accurate variety extent to which the product matches the consumer's expectations. In principle, customers prefer to have more rather than less versions of a product from which to choose. This motivates producers to offer a richer variety of goods. As a consequence, it brings a large amount of manufacturing complexity, and configuration conflicts may frequently occur. In order to avoid a situation in which a customer will select mutually incompatible components, product configurators usually recommend corrective actions for generating valid configurations. Nevertheless, the presence of infeasible configurations in customer options are negatively perceived by customers, and therefore it has an unfavorable impact on the sustainability of mass customization. One way to solve this problem is to eliminate, or at least reduce, mutually incompatible components. When considering the fact that eliminating all incompatible components may cause a rapid decrease in product variety, then the reduction of incompatible components can help to solve the product configuration problem. The proposed method aims to find a trade-off solution between minimizing configuration conflicts and maintaining a sufficient level of mass customization. Moreover, two supplementary methods for the determination of infeasible product configurations are proposed in this paper. The applicability and effectiveness of the proposed methods are demonstrated by two practical examples.
\end{abstract}

Keywords: positive complexity; negative complexity; infeasible configurations; product platform; customer's perception

\section{Introduction}

A great challenge facing original equipment manufacturers (OEMs) today is learning about which mass customization strategy is appropriate for specific product categories and markets, which large product variety should be offered, and how to manage product variety and its resulting complexity. Commonly, regarding the extent of customizable products, it is perceived by customers that the larger the product variety, the better [1]. This fact stimulates manufacturers to offer more and more individualized products in order to meet customer requirements [2]. It is obvious that such an approach may result in unexpected turbulence in their manufacturing systems, leading to, for example, higher direct production costs [3]. However, the higher costs themselves are not an issue if a company offers customization at acceptable prices. On the contrary, product configuration conflicts are becoming a serious problem that appear mostly when a high variety of products is offered. The presence of product configuration conflicts results in infeasible configurations, which are negatively perceived by customers due to uncertainty in customer choice. In order to solve this problem, different approaches are offered, recommending that designers take corrective actions such as removing selected components or adding new components $[4,5]$. In spite of this, so called ex-post interventions are limited. Moreover, Fraizer and Wells [6] showed that eliminating infeasible options through product configurators is not always 
viable. Therefore, product designers might reconsider such constraints because they trigger adverse reactions and/or customer disappointment. A promising solution to solve this problem is to eliminate, or at least reduce, mutually incompatible components in the early phase of the design process.

The main scope of this paper is to outline the necessary steps that are needed to solve this problem by changing the balance between infeasible product configurations and feasible product configurations. For this purpose, two methods for the determination of viable product configurations are proposed in order to find trade-off solution between minimizing configuration conflicts and maintaining a sufficient level of mass customization. These methods will be described and their feasibility will be demonstrated by two realistic examples. Finally, a discussion and conclusion with a summary drawn from current and future research relating to product configuration conflicts and sustainability of mass customization is presented.

\section{Related Work}

Mass customization as a business strategy can be very successful when sufficient varieties of products are offered at competitive prices with reasonable delivery times [7-10]. However, mass customization is an emerging paradigm, and may not be the panacea for all organizations [11]. According to Hadzistevic and Moraca [12], typical high product variety environments tend to come with a higher number of differentiated products that have a higher number of design changes, but Whitley et al. [13] argue that "consumers' perceptions of how many choices they prefer change depending on whether they intend to use an item for pleasure or to meet a functional need". Therefore, consumers motivated by pleasure prefer a large assortment, and customers looking only for functional products will be satisfied by a smaller assortment from which to choose. In this context, our research follows the behavior of the first group of customers. Aydogdu et al. [14] emphasized that product configuration conflicts cause enormous problems in the product or service design. Krus [15] proposed expressing the quality of a modular design through the rest of the design space that is outside the constrained design space by the term 'waste information entropy'. His approach inspired us to think in this way and adopt his idea with respect to the propriety of this complexity attribute.

Several studies, those by [16-19] for example, have underlined the fact that with the increasing demand for individual products and variants the transition from mass customization (MC) towards a personalized customization becomes more and more realistic. Some studies have considered advanced methods and techniques that lead to formal approaches for the design of entire product families in terms of MC. For example, a formal computer-assisted approach that addresses the requirements for the design of product family architecture products has been proposed by Bonev et al. [20]. A dynamic constraint satisfaction approach for configuring structural products under MC was presented in the studies of Huang et al. [21] and Yang et al. [22]. Matt and Rauch [23] focused their research on designs for the modular manufacturing of mass customized goods. High product variety in MC is often associated with complexity problems [24,25]. The positive impact of so called variety-induced complexity on sales performance has been presented, e.g., in works by Zhou et al. [26] and ElMaraghy et al. [27]. Tseng and Piller [28] developed a generic product variety structure consisting of the common product structure, variety parameters, and configuration constraints. A CAD-based approach for the automatic variation of three-dimensional product structure by changing the combination of parts, selecting the assembly method, and rearranging the assembly sequence was proposed by Chu et al. [29]. Such techniques allow product designers to determine the optimum level of the feasible rate of product customization.

Moreover, our research has been motivated by previous findings that restricted options are not perceived positively by individual users. In this context, authors, e.g., Mailharro [30], Antonelli et al. [31], Aldanondo et al. [32], Helo et al. [33], and Paul et al. [34] argue that infeasible configurations might be eliminated or minimized to avoid customer disappointment. 


\section{Methodological Framework}

In general, it is assumed that a large scale of product variety and its resulting complexity are inherently tied together. In order to establish a working definition for product variety-induced complexity, it is first supposed that complexity can be separated into structural and dynamic complexity concepts. Product variety-induced complexity belongs to the category of structural properties that describes only the static structure of a system by the number of system elements and their interrelationships [35]. Abdelkafi [36] developed a comprehensive framework explaining the term 'variety-induced complexity', assuming that this aspect of complexity is directly associated with the extent of product variety and not with the sates of the system. He emphasized that such a view on complexity differs a great deal from its meaning in cybernetics. Hu et al. [37] proposed a unified measure of complexity by combining both product variety and assembly process information, and developed models for evaluating complexity in assembly systems. Trattner et al. [38] argued that there is no strong relationship between the complexity of the products produced and any measure of manufacturing operational performance. Therefore, taking into account that every effort to find an adequate definition for product variety-induced complexity is not trivial, we further assume that variety-induced complexity relates to the amount of product variants.

Second, it is important to distinguish between an external customers' views on variety-induced complexity problems and the internal viewpoints of manufacturers. In this context, internal complexity can be defined as the amount of input, information, or energy that the manufacturing system receives from its environment [39]. External complexity relates to customers experience during the product selection process in extensive variety environments [40]. Our focus, in this research work, is only on the external complexity that reflects the number of realistic product configurations, $\mathrm{N}_{\text {real }}$, offered to customers as well as the number of infeasible product variants, $\mathrm{N}_{\text {inf }}$, that can occur during product configuration by the customers.

The first question when dealing with infeasible product configurations due to incompatible components concerns the distinction between customer perceptions of available product configurations and infeasible product configurations. The number of available product configurations are perceived by customers positively, i.e., the larger the better [20]. Therefore, uncertainty related to product variety reflecting only the quantity of realistic product configurations can be viewed as a positive source of variety-induced complexity. By contrast, infeasible product configurations are undesirable for customers [41]. Thus, the smaller the better criterion can be taken as a preliminary assessment of the presence of infeasible product configurations. Accordingly, the related variety-based complexity reflecting relative rate of $\mathrm{N}_{\text {inf }}$ in the total amount of product configurations, $\mathrm{N}_{\text {total, }}$ is attributed here as a negative source of variety-induced complexity.

Based on the above, product configuration conflicts negatively affect the sustainability of mass customization. When following the words of Lord Kelvin, "If you cannot measure it, you cannot improve it" the subsequent challenge is to measure this impact in a way that is quantifiable as well as qualitative. For this purpose, it is reasonable to employ Axiomatic Design Theory [42] for selecting the best design parameters (DPs) to satisfy the functional requirements (FRs). The second axiom states that when several alternative designs satisfy the first axiom, then the best design is the one with minimal additional information. In other words, design is good if its additional information content equals zero. Quantity of information content can be constructed by using the probability density function, as shown in Figure 1, where the design range represents the extent of the FRs, the system range corresponds with the DPs, and the common range is the mutual area between the design range and the system range. 


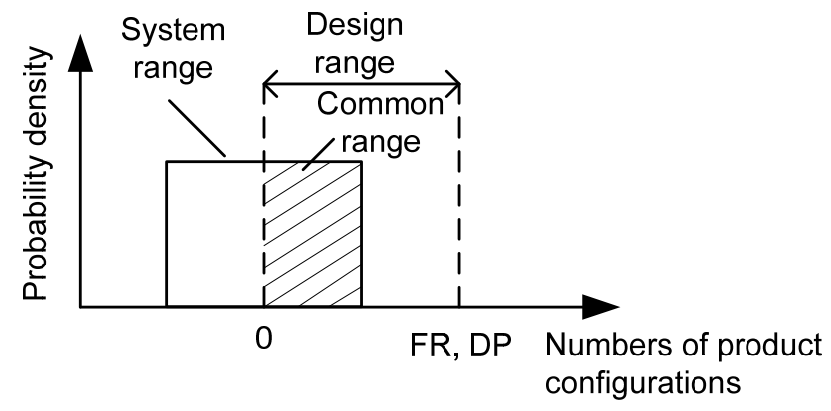

Figure 1. Probability density function of uniform distribution. Note: functional requirements (FR), design parameters (DP).

According to information theory, the information content of an event, $E$, is expressed as follows:

$$
I(E)=-\log _{2}(p(E))=\log _{2}\left(\frac{1}{p(E)}\right)
$$

Then, additional information content of the design space can be calculated by formula [43]:

$$
I=\log _{2}\left(\frac{\text { System range }}{\text { Common range }}\right)
$$

In our specific case we consider that:

Design range is represented by the $N_{\text {total }}$;

Common range is represented by the $N_{\text {real }}$;

System range is identical to the design range because, if $N_{\text {real }}=N_{\text {total }}$, then $N_{\text {inf }}=0$, i.e., information content is optimal because $I=0$, and if $N_{\text {real }} \neq N_{\text {total, }}$, then $N_{\text {inf }} \neq 0$; i.e., information content is not optimal because $I \neq 0$.

Based on that amount of the additional information content, i.e., negative complexity of the product design variety, $\left(C_{N}\right)$ can be expressed as:

$$
C_{N}=\log _{2} N_{\text {total }}-\log _{2} N_{\text {real }}
$$

Moreover, gradual categorization of the notion of negative complexity is shown in Figure 2.

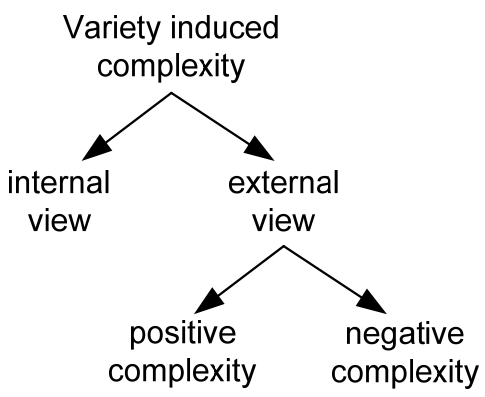

Figure 2. Classification of variety-induced complexity in terms of mass customization.

In order to apply this methodology to product design projects, figures for $\mathrm{N}_{\text {total }}$ and $\mathrm{N}_{\text {real }}$ are first determined and, subsequently, figures for $\mathrm{N}_{\text {inf }}$ are enumerated. $\mathrm{N}_{\text {total }}$ can be calculated using common combinatorial rules, while standard procedures for the enumeration of $\mathrm{N}_{\text {real }}$ are not available. Therefore, the two different methods for determining $\mathrm{N}_{\text {real }}$ are presented in the next section by using the realistic Case 1. Consecutively, the realistic Case 2 demonstrates the applicability of the methodological framework to measure the negative complexity of the product design variety. 


\section{Application of Methodology on Real Case Studies}

As mentioned above, one of the aims of this section is to show how to calculate the number of realistic product configurations when restrictions between product components occur. Prior to this, it is beneficial to classify the main types of product components (PCs), which are as follows: Stable components (S), which are comprised in all possible configuration; Optional components $(\mathrm{O})$, which are chosen according to the customer's requirements and are alterable in any combination, including the case where customers do not choose any of the offered options; Restricted optional components (RO) that can be selected from a set of different components according to exactly specified restriction conditions. Restrictions can be determined using at least three types of the volition rules: minimum, maximum, and particular requirements on selection of optional components.

The particular volition rule can be specified in a simple way by combinatorial number $\left(\begin{array}{l}k \\ l\end{array}\right)$, where $l$ defines the required number of selected RO from the available number, $k$, of $\mathrm{RO}$, while $1 \leq l<k$.

Selection by minimum volition rule $\left(\begin{array}{c}k \\ \operatorname{lmin}\end{array}\right)$ should be limited to a certain number or more.

Selection by maximum volition rule $\left(\begin{array}{c}k \\ \operatorname{lmax}\end{array}\right)$ should be limited to a certain number or less.

It should be noted that the number of possible product configurations depends practically on the number of optional components on the number of restricted optional components described by volitions rules for their selection.

As mentioned earlier, two methods concerning how to enumerate $\mathrm{N}_{\text {real }}$ will be presented. The first is based on graphical presentation using multidimensional matrices, whereas the second one uses proposed calculator software, which enumerates $\mathrm{N}_{\text {real }}$ using two-dimensional matrices between two complementary types of optional components and their variants. Both of the mentioned methods will be applied to Case 1 , and the software based method will be applied to Case 2 .

\subsection{Case 1}

The ways to enumerate $\mathrm{N}_{\text {real }}$ using the graphical method and the calculator-based method with component restrictions are described through the example of a customizable mobile phone containing one stable component, namely Calls; two optional components, specifically GPS and Media; and one restricted optional component, i.e., Screen with specific volition rule $\left(\begin{array}{l}3 \\ 1\end{array}\right)$ and defined restrictions, as shown in Figure 3.

\subsubsection{Enumeration of Possible Product Configurations Using the Graphical Method}

To enumerate the number of $\mathrm{N}_{\text {inf }}$ using the graphical method, the following procedure is proposed. Let us start, for example, with the restricted optional component, i.e., Screen, for which we select, e.g., Color screen (CSc.). Other options are Basic screen (BSc.) and High resolution screen (HRSc.). It is then possible to construct an incidence sub-matrix for the Color screen option and a stable component-Calls. Because there is no restriction, Color screen as an option can be combined with the Calls component (see Figure 4a). Then, a three-dimensional matrix is created with relations between the Color screen component, the Calls component, and the optional GPS component. Note that a mobile phone configuration without GPS can also be designed (marked in the matrix as without GPS). There are no restrictions in this case (see Figure $4 b$ ), therefore, a four-dimensional matrix of relations is subsequently constructed to determine the number of restricted product configurations with Color screen by adding a fourth dimension-Media, with two optional components. It is possible to create four choices here, such as only the MP3 component, only the Camera component, the MP3 and Camera components together, or none of these components. Only one restricted option occurs in this four-dimensional matrix and, accordingly, Camera must be combined with a compatible type of screen (Camera requires High resolution screen in its product configuration). Subsequently, it is 
possible to identify two options for Media-the presence of MP3 in the final product configuration or no Media components (see Figure 4c).

a)

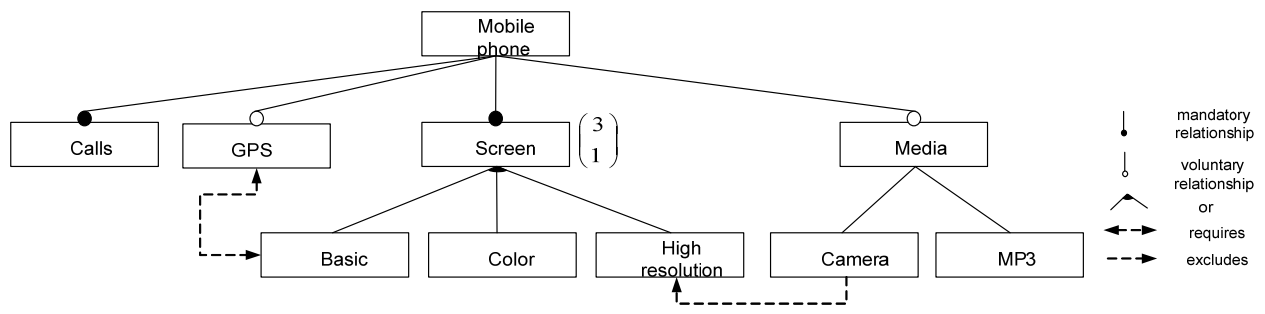

b)

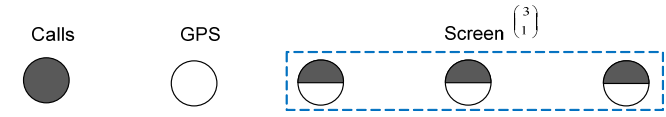

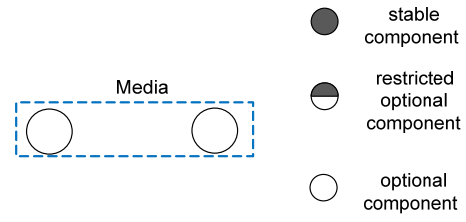

Figure 3. (a) Feature diagram of mobile phone; (b) Product component structure.

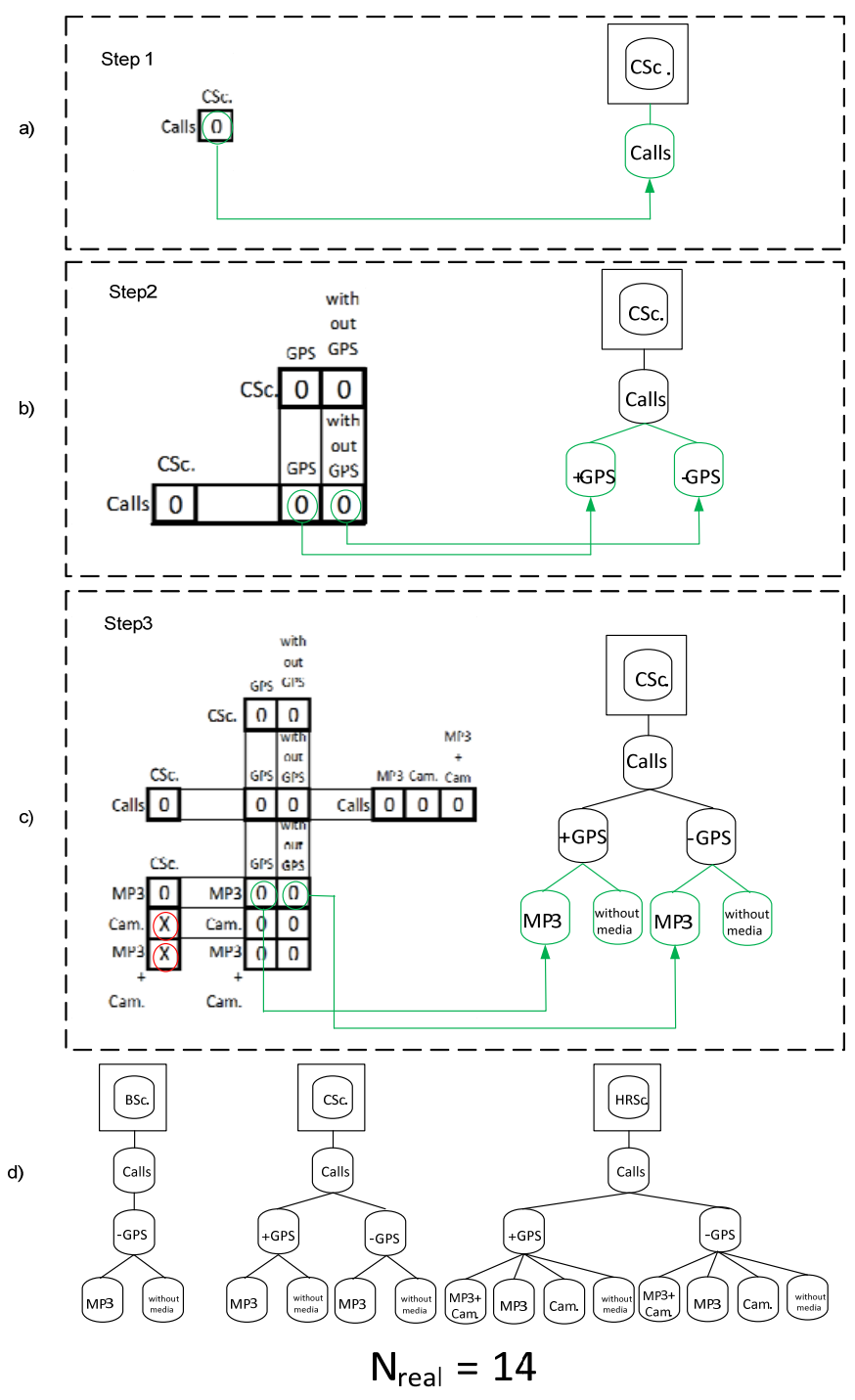

Figure 4. Procedure for transforming incidence matrices into product component structure with the initial component Color screen: (a) Step 1; (b) Step 2; (c) Step 3; (d) Generated $\mathrm{N}_{\text {real }}$ respecting defined restrictions. 
Consecutively, the sub-procedure depicted in Figure $4 \mathrm{a}-\mathrm{c}$ has to be repeated for the rest of the components, namely, Basic screen and High resolution screen. Then one can obtain 14 realistic product configurations of the mobile phone in total (see Figure 4d).

\subsubsection{Enumeration of Possible Product Configurations Using Software}

The second method generates $\mathrm{N}_{\text {real }}$ using the proposed online calculator [44]. As this method is based on two-dimensional matrices, it allows the calculation of $\mathrm{N}_{\text {real }}$ between two complementary types of optional components, while restrictions can occur. Let us use the previous example-a mobile phone- - to calculate $\mathrm{N}_{\text {real }}$. Firstly, we start with two components; Screen and Media. To obtain the correct number of $\mathrm{N}_{\text {real }}$, one more variant of Media has to be considered, i.e., the option without media. Media variations are as follows: MP3 (V22), Camera (V21), MP3 + Camera (V23), or configuration without media (V24). The initial step of how to use the online calculator for $\mathrm{N}_{\text {real }}$ is to define "Value Problems", known as an $m \times n$ matrix, which has $m$ vertical columns and $n$ horizontal rows. In our case, $m$ presents Screen options (BSc. (V11), CSc. (V12), and HRSc. (V13)) and $n$ presents Media options, then $m \times n=3 \times 4$. Subsequently, it is possible to assign defined restrictions (BSc. and CSc) in columns V21 and V23 of this matrix by checking the white boxes, which turn red, as can be seen in Figure 5a. Finally, the online calculator generates $\mathrm{N}_{\text {real }}$, respecting the restrictions. In the case of the generation of $\mathrm{N}_{\text {total }}$ without restrictions, we leave the white boxes unchecked.
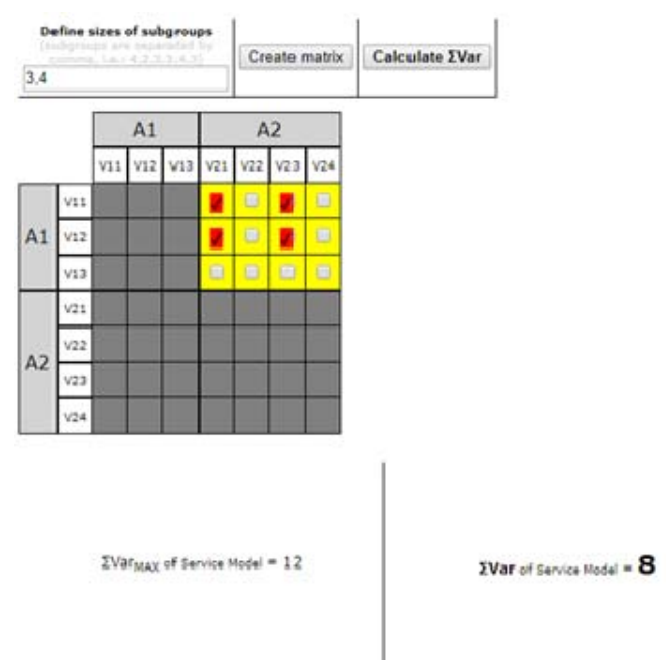

a)
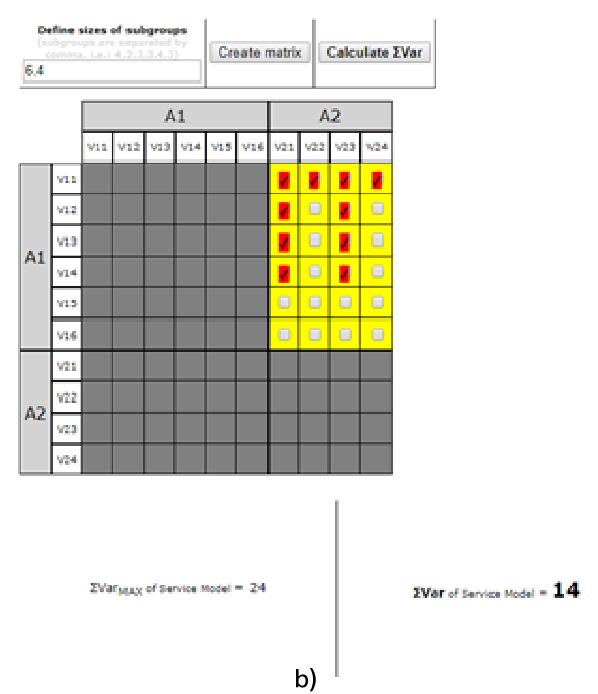

b)

Figure 5. (a) Calculator software window with calculation of preliminary $\mathrm{N}_{\text {total }}$ and $\mathrm{N}_{\text {real }}$. (b) Calculator software window with calculation of final $\mathrm{N}_{\text {total }}$ and $\mathrm{N}_{\text {real }}$.

To calculate the final $\mathrm{N}_{\text {real, }}$ when restrictions are included for all the components of the mobile phone, it is necessary to join together Screen and Media into one component type with its variations (BSc. with GPS (V21); BSc. without GPS (V22); CSc. with GPS (V23); CSc. without GPS (V24); HRSc. with GPS (V25), and HRSc. without GPS (V26)), which creates the rows of the new two-dimensional matrix. The columns of this matrix will form the Media component type with its variants. The component Calls, being the stable one, is included in each configuration, and it does not affect the number of $\mathrm{N}_{\text {real }}$. For this reason, only the mentioned components and their variants are included in this procedure. Then, it is necessary to define in the software window "Define sizes of subgroups" $m \times n=6 \times 4$, and to assign restrictions in the new matrix, which are as follows: GPS cannot be in configuration with a BSc., Camera and MP3 + Camera cannot be in configuration with a BSc. or a CSc. Finally, we obtain the $\mathrm{N}_{\text {real }}$ and the $\mathrm{N}_{\text {total }}$ (see Figure $5 \mathrm{~b}$ ). 
According to the obtained results by the proposed calculator, the number of $\mathrm{N}_{\text {real }}$ is 14 , which is the same as that gained by using the graphically based method. Finally, $\mathrm{N}_{\text {inf }}$ is enumerated as $\mathrm{N}_{\text {total }}-\mathrm{N}_{\text {real }}=10$.

\subsection{Case \#2}

The purpose of this section is twofold: (1) To describe the calculator-based method of enumerating $\mathrm{N}_{\text {real }}$ on a realistic case, and (2) to demonstrate the applicability of the methodology for identification and reduction of negative complexity in designing product platforms and sub-platforms.

\subsubsection{Description of the Calculator-Based Method}

The calculator-based procedure will be described using the two inter-operating parts of a front drivetrain bicycle module, which can be found on every model of bicycle. This product sub-platform consists of nine types of gear component and two types of front drivetrain parts each with a different chain stay angle (CSA). Each of the nine groups differs from the others in the specific number of related components to be combined with the selected alternative of the front drivetrain (FD). For example, Gear type 1 can be combined with six Front Crank sets (FC11-FC16). In Table 1, elements of the matrix noted with " $X$ " stand for a restriction/incompatibility.

With this range of components, we can construct an incidence matrix with sizes of subgroups $m \times n=38 \times 19$ using the same principle as described in Section 4.1.2. First, we add into the software window the names of the columns marked as V21 to V219 and the names of the rows marked as V11 to V138, representing the bicycle components. Next we assign restrictions between the components by checking the white boxes. Subsequently, by clicking on "Calculate $\sum$ Var" we obtain $\mathrm{N}_{\text {real }}=239$ product configurations, as depicted in Figure 6.

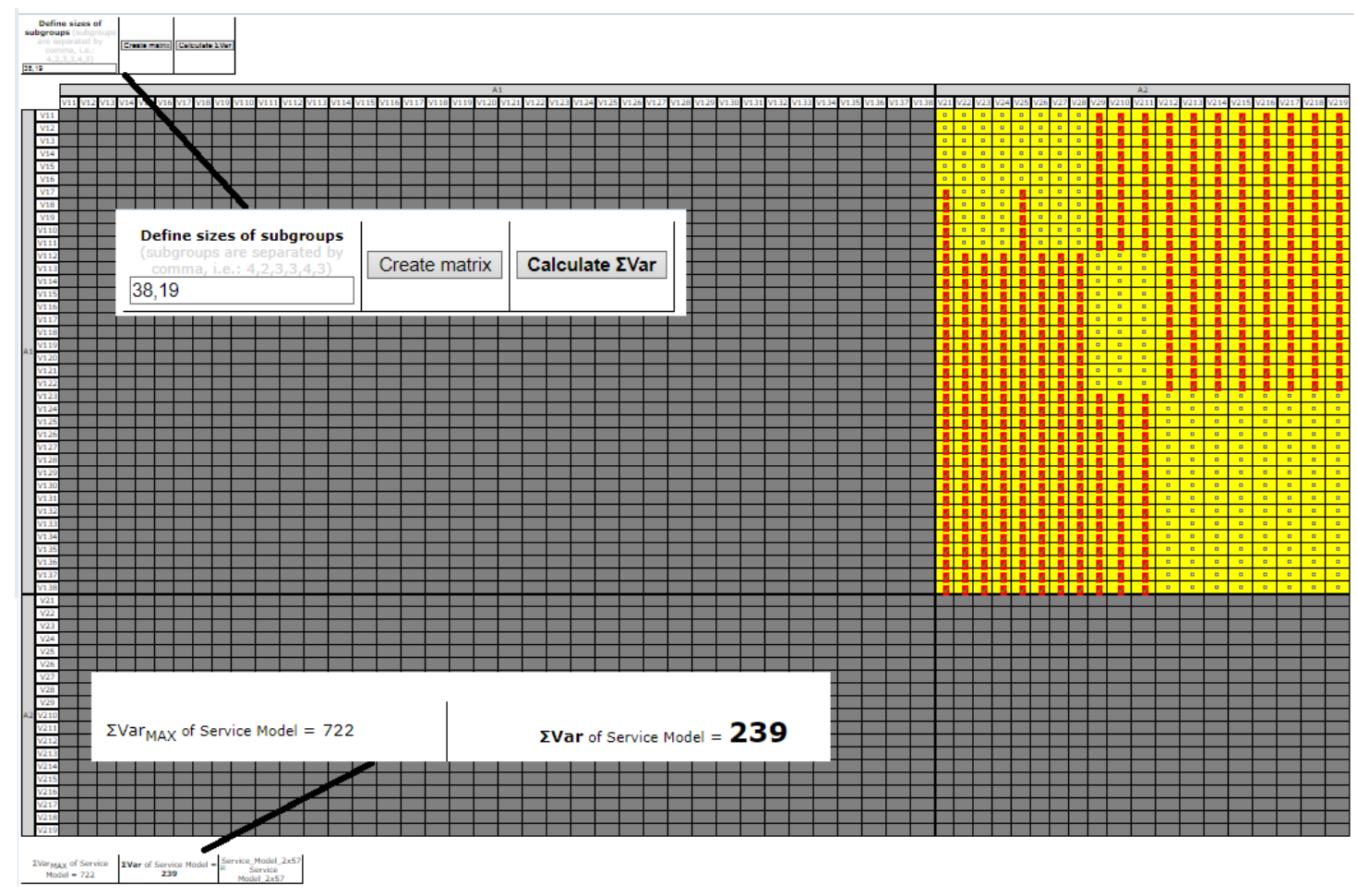

Figure 6. Generated number of $\mathrm{N}_{\text {total }}$ and $\mathrm{N}_{\text {real }}$ using software.

Finally, the number of infeasible product configurations is enumerated as $\mathrm{N}_{\text {total }}-\mathrm{N}_{\text {real }}=483$. 
Table 1. Bicycle components presented by compatibility platform $D_{0}$ for gears and front drive train.

\begin{tabular}{|c|c|c|c|c|c|c|c|c|c|c|c|c|c|c|c|c|c|c|c|c|}
\hline \multicolumn{2}{|c|}{ Sub-Platform $\mathrm{D}_{0}$} & \multicolumn{19}{|c|}{ Front Drivetrain (FD) } \\
\hline & & \multicolumn{13}{|c|}{ FD Type 1} & \multicolumn{6}{|c|}{ FD Type 2} \\
\hline \multicolumn{2}{|c|}{ Chain Stay Angle (CSA) } & \multicolumn{9}{|c|}{ CSA 1} & \multicolumn{4}{|c|}{ CSA 2} & \multicolumn{6}{|c|}{ CSA 3} \\
\hline Gears & $\begin{array}{c}\text { Front } \\
\text { Crankset (FC) }\end{array}$ & FD11 & FD12 & FD13 & FD14 & FD15 & FD16 & FD17 & FD18 & FD21 & FD22 & FD23 & FD31 & FD32 & FD33 & FD34 & FD35 & FD36 & FD37 & FD38 \\
\hline \multirow{6}{*}{ Gear type 1} & FC11 & & & & & & & & & $x$ & $x$ & $x$ & $x$ & $x$ & $x$ & $x$ & $x$ & $x$ & $x$ & $x$ \\
\hline & FC12 & & & & & & & & & $x$ & $x$ & $x$ & $x$ & $x$ & $x$ & $x$ & $x$ & $x$ & $x$ & $x$ \\
\hline & FC13 & & & & & & & & & $x$ & $x$ & $x$ & $x$ & $x$ & $x$ & $x$ & $x$ & $x$ & $x$ & $x$ \\
\hline & FC14 & & & & & & & & & $x$ & $x$ & $x$ & $x$ & $x$ & $x$ & $x$ & $x$ & $x$ & $x$ & $x$ \\
\hline & FC15 & & & & & & & & & $x$ & $x$ & $x$ & $x$ & $x$ & $x$ & $x$ & $x$ & $x$ & $x$ & $x$ \\
\hline & FC16 & & & & & & & & & $x$ & $x$ & $x$ & $x$ & $x$ & $x$ & $x$ & $x$ & $x$ & $x$ & $x$ \\
\hline \multirow{5}{*}{ Gear type 2} & FC21 & $x$ & & & & $x$ & & & & $x$ & $x$ & $x$ & $x$ & $x$ & $x$ & $x$ & $x$ & $x$ & $x$ & $x$ \\
\hline & FC22 & $x$ & & & & $x$ & & & & $x$ & $x$ & $x$ & $x$ & $x$ & $x$ & $x$ & $x$ & $x$ & $x$ & $x$ \\
\hline & FC23 & $x$ & & & & $x$ & & & & $x$ & $x$ & $x$ & $x$ & $x$ & $x$ & $x$ & $x$ & $x$ & $x$ & $x$ \\
\hline & FC24 & $x$ & & & & $x$ & & & & $x$ & $x$ & $x$ & $x$ & $x$ & $x$ & $x$ & $x$ & $x$ & $x$ & $x$ \\
\hline & FC25 & $x$ & & & & $x$ & & & & $x$ & $x$ & $x$ & $x$ & $x$ & $x$ & $x$ & $x$ & $x$ & $x$ & $x$ \\
\hline \multirow{8}{*}{ Gear type 3} & FC31 & $x$ & $x$ & $x$ & $x$ & $x$ & $x$ & $x$ & $x$ & & & & $x$ & $x$ & $x$ & $x$ & $x$ & $x$ & $x$ & $x$ \\
\hline & FC32 & $x$ & $x$ & $x$ & $x$ & $x$ & $x$ & $x$ & $x$ & & & & $x$ & $x$ & $x$ & $x$ & $x$ & $x$ & $x$ & $x$ \\
\hline & FC33 & $x$ & $x$ & $x$ & $x$ & $x$ & $x$ & $x$ & $x$ & & & & $x$ & $x$ & $x$ & $x$ & $x$ & $x$ & $x$ & $x$ \\
\hline & FC34 & $x$ & $x$ & $x$ & $x$ & $x$ & $x$ & $x$ & $x$ & & & & $x$ & $x$ & $x$ & $x$ & $x$ & $x$ & $x$ & $x$ \\
\hline & FC35 & $x$ & $x$ & $x$ & $x$ & $x$ & $x$ & $x$ & $x$ & & & & $x$ & $x$ & $x$ & $x$ & $x$ & $x$ & $x$ & $x$ \\
\hline & FC36 & $x$ & $x$ & $x$ & $x$ & $x$ & $X$ & $x$ & $x$ & & & & $x$ & $x$ & $x$ & $x$ & $x$ & $x$ & $x$ & $x$ \\
\hline & FC37 & $x$ & $x$ & $x$ & $x$ & $x$ & $x$ & $x$ & $x$ & & & & $x$ & $x$ & $x$ & $x$ & $x$ & $x$ & $x$ & $x$ \\
\hline & FC38 & $x$ & $x$ & $x$ & $x$ & $x$ & $x$ & $x$ & $x$ & & & & $x$ & $x$ & $x$ & $x$ & $x$ & $x$ & $x$ & $x$ \\
\hline \multirow{3}{*}{ Gear type 4} & FC41 & $x$ & $x$ & $x$ & $x$ & $x$ & $x$ & $x$ & $x$ & & & & $x$ & $x$ & $x$ & $x$ & $x$ & $x$ & $x$ & $x$ \\
\hline & FC42 & $x$ & $x$ & $x$ & $x$ & $x$ & $x$ & $x$ & $x$ & & & & $x$ & $x$ & $x$ & $x$ & $x$ & $x$ & $x$ & $x$ \\
\hline & FC43 & $x$ & $x$ & $x$ & $x$ & $x$ & $x$ & $x$ & $x$ & & & & $x$ & $x$ & $x$ & $x$ & $x$ & $x$ & $x$ & $x$ \\
\hline Gear type 5 & FC5 & $x$ & $x$ & $x$ & $x$ & $x$ & $x$ & $x$ & $x$ & $x$ & $x$ & $x$ & & & & & & & & \\
\hline Gear type 6 & FC6 & $x$ & $x$ & $x$ & $x$ & $x$ & $x$ & $x$ & $x$ & $x$ & $x$ & $x$ & & & & & & & & \\
\hline
\end{tabular}


Table 1. Cont.

\begin{tabular}{|c|c|c|c|c|c|c|c|c|c|c|c|c|c|c|c|c|c|c|c|c|}
\hline \multicolumn{2}{|c|}{ Sub-Platform $D_{0}$} & \multicolumn{19}{|c|}{ Front Drivetrain (FD) } \\
\hline 50 & 0 & \multicolumn{13}{|c|}{ FD Type 1} & \multicolumn{6}{|c|}{ FD Type 2} \\
\hline \multicolumn{2}{|c|}{ Chain Stay Angle (CSA) } & \multicolumn{9}{|c|}{ CSA 1} & \multicolumn{4}{|c|}{ CSA 2} & \multicolumn{6}{|c|}{ CSA 3} \\
\hline Gears & $\begin{array}{c}\text { Front } \\
\text { Crankset (FC) }\end{array}$ & FD11 & FD12 & FD13 & FD14 & FD15 & FD16 & FD17 & FD18 & FD21 & FD22 & FD23 & FD31 & FD32 & FD33 & FD34 & FD35 & FD36 & FD37 & FD38 \\
\hline \multirow{5}{*}{ Gear type 7} & FC71 & $x$ & $x$ & $x$ & $x$ & $x$ & $x$ & $x$ & $x$ & $x$ & $x$ & $x$ & & & & & & & & \\
\hline & FC72 & $x$ & $x$ & $x$ & $x$ & $x$ & $x$ & $x$ & $x$ & $x$ & $x$ & $x$ & & & & & & & & \\
\hline & FC73 & $x$ & $x$ & $x$ & $x$ & $x$ & $x$ & $x$ & $x$ & $x$ & $x$ & $x$ & & & & & & & & \\
\hline & FC74 & $x$ & $x$ & $x$ & $x$ & $x$ & $x$ & $x$ & $x$ & $x$ & $x$ & $x$ & & & & & & & & \\
\hline & FC75 & $x$ & $x$ & $x$ & $x$ & $x$ & $x$ & $x$ & $x$ & $x$ & $x$ & $x$ & & & & & & & & \\
\hline \multirow{5}{*}{ Gear type 8} & FC81 & $x$ & $x$ & $x$ & $x$ & $x$ & $x$ & $x$ & $x$ & $x$ & $x$ & $x$ & & & & & & & & \\
\hline & FC82 & $x$ & $x$ & $x$ & $x$ & $x$ & $x$ & $x$ & $x$ & $x$ & $x$ & $x$ & & & & & & & & \\
\hline & FC83 & $x$ & $x$ & $x$ & $x$ & $x$ & $x$ & $x$ & $x$ & $x$ & $x$ & $x$ & & & & & & & & \\
\hline & FC84 & $x$ & $x$ & $x$ & $x$ & $x$ & $x$ & $x$ & $x$ & $x$ & $x$ & $x$ & & & & & & & & \\
\hline & FC85 & $x$ & $x$ & $x$ & $x$ & $x$ & $x$ & $x$ & $x$ & $x$ & $x$ & $x$ & & & & & & & & \\
\hline \multirow{4}{*}{ Gear type 9} & FC91 & $x$ & $x$ & $x$ & $x$ & $x$ & $x$ & $x$ & $x$ & $x$ & $x$ & $x$ & & & & & & & & \\
\hline & FC92 & $x$ & $x$ & $x$ & $x$ & $x$ & $x$ & $x$ & $x$ & $x$ & $x$ & $x$ & & & & & & & & \\
\hline & FC93 & $x$ & $x$ & $x$ & $x$ & $x$ & $x$ & $x$ & $x$ & $x$ & $x$ & $x$ & & & & & & & & \\
\hline & FC94 & $x$ & $x$ & $x$ & $x$ & $x$ & $x$ & $x$ & $x$ & $x$ & $x$ & $x$ & & & & & & & & \\
\hline
\end{tabular}




\subsubsection{Resolving Product Configuration Conflicts}

In order to resolve the product configuration conflicts, one can see the two possible ways that can be used to eliminate or at least reduce mutually incompatible components. When considering the fact that eliminating all incompatible components may cause a rapid decrease in product variety, then reduction of incompatible components seems to be a more useful approach. Therefore, it appears to be reasonable to generate derived alternatives of the original product sub-platforms, in which selected incompatible components will be omitted. For this purpose, this method can be used to generate three other alternative product platforms, $D_{1}-D_{3}$, in which selected incompatible components will be gradually removed from the initial design platform, $D_{0}$, where the complete design space $\left(\mathrm{N}_{\text {total }}\right)$ is defined by 722 configurations, and the restricted design space $\left(\mathrm{N}_{\text {real }}\right)$ is represented by 239 configurations.

In this task, in order to propose a possible concurrent product platforms at once, let us remove Gear type 3, which includes 8 crank sets (FC31-FC38), from $D_{0}$. This group of components was selected to be excluded from $D_{0}$, using the criterion of the highest density of restrictions. In this way we obtained platform $D_{1}$, which is defined by $\mathrm{N}_{\text {total1 }}=570$ drivetrain configurations, from which 215 are viable.

Afterwards, for determination of the platform, $D_{2}$, we proceed towards the reduction of Gear type 4, which includes three crank sets (FC41, FC42, and FC43). We obtained platform $D_{2}$ with $\mathrm{N}_{\text {total2 }}=513$ drivetrain configurations and $\mathrm{N}_{\text {real }}=206$ restricted (viable) product configurations.

In order to provide the next alternative product platform, $D_{3}$, two FDs, namely FD11 and FD15, can be removed from $D_{2}$ due to the high number of restrictions related to these two components. Then, $D_{3}$ is represented by $\mathrm{N}_{\text {total }}=459$ drivetrain configurations and $\mathrm{N}_{\text {real }}=194$ feasible product configurations.

In the next step, the obtained number of configurations are used to quantify and compare the values of negative complexity of the concurrent product sub-platforms, as depicted in Table 2.

Table 2. Comparison of the product sub-platforms.

\begin{tabular}{clcll}
\hline & \multicolumn{1}{c}{$\boldsymbol{D}_{\mathbf{0}}$} & $\boldsymbol{D}_{\mathbf{1}}$ & $\boldsymbol{D}_{\mathbf{2}}$ & $\boldsymbol{D}_{\mathbf{3}}$ \\
\hline $\mathrm{N}_{\text {total }}$ & 722 conf. & 570 conf. & 513 conf. & 459 conf. \\
\hline $\mathrm{N}_{\text {real }}$ & 239 conf. & 215 conf. & 206 conf. & 194 conf. \\
\hline $\mathrm{N}_{\text {inf }}$ & 483 conf. & 355 conf. & 307 conf. & 265 conf. \\
\hline $\begin{array}{c}\text { Entropy of design space } \\
\text { (without constraints) }\end{array}$ & 9.50 bits & 9.16 bits & 9.00 bits & 8.84 bits \\
\hline $\begin{array}{c}\text { Entropy of constrained } \\
\text { design space }\end{array}$ & 7.90 bits & 7.75 bits & 7.69 bits & 7.60 bits \\
\hline $\mathrm{C}_{\mathrm{N}}$ & 1.60 bits & 1.41 bits & 1.31 bits & 1.24 bits \\
\hline
\end{tabular}

\section{Discussion}

Firstly, as regards the two proposed computational methods to calculate $\mathrm{N}_{\text {real }}$, it is important to note that the graph-based method approach using more dimensional matrices is not suitable for large numbers of components, while the software-based method is intended to enumerate numbers of module variations and/or product configurations with large numbers of optional product components. In addition, the graph based method can be used as the theoretical basis for developing an effective concurrent software programming technique that could be used for the same purpose.

Coming back to the results obtained by generating the alternative product platforms $D_{1}-D_{3}$, it is evident that $D_{3}$ is has the smallest value of negative complexity. In other words, this product platform has a minimal negative effect on the customers' perception of the company product offer. 


\section{Conclusions}

Summarily, it is worth noting that sustainable mass customization projects are oriented on the building of trust with customers. This also means that each potential negative perception of risk must be eliminated or reduced because, otherwise, it could cause customers to feel reluctant to invest their time and effort in mass customization and may prefer a standard product instead. It is quite obvious that a universal solution to this problem is rather counterintuitive. Theoretically, the best way is to eliminate all configuration constraints by product design changes, if possible. Alternatively, the next effort could be focused on eliminating infeasible options through product configurators. Computational experiments have clearly shown that designers can generate alternative product platforms and identify their negative complexity through the proposed method. However, only designers of specific products can decide which product platform is the best for them, according to the given criterion.

According to related experts, each different MC sector requires a specific approach to solve configuration conflicts, and therefore elimination of infeasible options through product configurators is significantly difficult. In this context, experts recommend that this type of configurators should be capable of analyzing inconsistencies between components during the selection process and propose to the customers the minimum changes required to achieve a resolution. A complementary solution to the previous one is offered in the present study.

The proposed method has been theoretically verified through the investigation of several realistic problems, two of which have been demonstrated in this study. The next stage of research will be focused on the willingness of manufacturers to reduce the number of incompatible components in their product platforms, and the exploration of the potential benefits of such decisions.

Finally, it can be stated that the proposed method combines known elements of knowledge in a novel way.

Author Contributions: V.M. proposed the whole structure of this paper, provided the introduction and the related work methodology framework, and summarized the findings in the conclusion section. Z.S. worked on the selection and application of methodology on real case studies. All authors have read and agreed to the published version of the manuscript.

Funding: This research was funded by the European Union's Horizon 2020 research and innovation program under the Marie Skłodowska-Curie, grant number 734713 and by the KEGA project Nr. 025TUKE-4/2020 granted by the Ministry of Education of the Slovak Republic.

Conflicts of Interest: The authors declare no conflict of interest.

\section{References}

1. Da Silveira, G.; Borenstein, D.; Fogliatto, F.S. Mass customization: Literature review and research directions. Int. J. Prod. Econ. 2001, 20, 1-13. [CrossRef]

2. Schuh, G.; Reuter, C.; Hauptvogel, A. Increasing collaboration productivity for sustainable production systems. Procedia CIRP 2015, 29, 191-196. [CrossRef]

3. Gilmore, J.H.; Pine, B.J. The four faces of mass customization. Harv. Bus. Rev. 1997, 75, 91-101.

4. Yang, D.; Dong, M. A constraint satisfaction approach to resolving product configuration conflicts. Adv. Eng. Inform. 2012, 26, 592-602. [CrossRef]

5. Liu, Y.; Liu, Z. Multi-objective product configuration involving new components under uncertainty. J. Eng. Des. 2010, 21, 473-494. [CrossRef]

6. Fraizer, S.; Wells, R. System for Presenting Customer Constrained Purchase Choices in an On-Line Store. WO Patent 2001091019 A1 filed, 29 November 2001.

7. Cox, W.M.; Alm, R. The Right Stuff-America's Move to Mass Customization; Federal Reserve Bank of Dallas Annual Report; Federal Reserve Bank of Dallas: Dallas, TX, USA, 1998; pp. 3-26.

8. Funke, M.; Ruhwedel, R. Product variety and economic growth: Empirical evidence from the OECD countries. IMF Staff. Pap. 2001, 48, 225-242. [CrossRef]

9. Modrak, V.; Bednar, S.; Soltysova, Z. Application of axiomatic design-based complexity measure in mass customization. Procedia CIRP 2016, 50, 607-612. [CrossRef] 
10. Forza, C.; Salvador, F. Application support to product variety management. Int. J. Prod. Res. 2008, 46, 817-836. [CrossRef]

11. Pollard, D.; Chuo, S.; Lee, B. Strategies for mass customization. J. Bus. Econ. Res. (JBER) 2008, 6, 77-86.

12. Hadzistevic, M.; Moraca, S. Networks and Quality Improvement. Int. J. Qual. Res. 2009, 3, 353-361.

13. Whitley, S.C.; Trudel, R.; Kurt, D. How many versions of a product do consumers really want? Harv. Bus. Rev. 2018. Available online: https://hbr.org/2018/06/how-many-versions-of-a-product-do-consumers-really-want, (accessed on 27 June 2018).

14. Aydogdu, A.A.; Saka, M.P. Design optimization of real-world steel space frames using artificial bee colony algorithm with Levy flight distribution. Adv. Eng. Softw. 2016, 92, 1-14. [CrossRef]

15. Krus, P. Design space configuration for minimizing designinformation entropy. In ICoRD'15-Research into Design AcrossBoundaries Volume 1: Theory, Research Methodology, Aesthetics, Human Factors and Education, vol. 34 of Smart Innovation, Systems and Technologies; Springer: New Delhi, India, 2015; pp. 51-60.

16. Matt, D.; Rauch, E.; Dallasega, P. Trends towards distributed manufacturing systems and modern forms for their design. Procedia CIRP 2015, 33, 185-190. [CrossRef]

17. Modrak, V.; Marton, D.; Bednar, S. The influence of mass customization strategy on configuration complexity of assembly systems. Procedia CIRP 2015, 33, 538-543. [CrossRef]

18. Wang, Y.; Ma, H.S.; Yang, J.H.; Wang, K.S. Industry 4.0: A way from mass customization to mass personalization production. Adv. Manuf. 2017, 5, 311-320. [CrossRef]

19. Zhang, X.; Ming, X.; Liu, Z.; Qu, Y.; Yin, D. State-of-the-art review of customer to business (C2B) model. Comput. Ind. Eng. 2019, 132, 207-222. [CrossRef]

20. Bonev, M.; Hvam, L.; Clarkson, J.; Maier, A. Formal computer-aided product family architecture design for mass customization. Comput. Ind. 2015, 74, 58-70. [CrossRef]

21. Huang, Y.; Liu, H.; Ng, W.K.; Song, B.; Li, X. Automating knowledge acquisition for constraint-based product configuration. J. Manuf. Technol. Manag. 2008, 19, 744-754. [CrossRef]

22. Yang, D.; Dong, M.; Chang, X.K. A dynamic constraint satisfaction approach for configuring structural products under mass customization. Eng. Appl. Artif. Intell. 2014, 25, 1723-1737. [CrossRef]

23. Matt, D.T.; Rauch, E. Design of a Network of Scalable Modular Manufacturing Systems to Support Geographically Distributed Production of Mass Customized Goods. Procedia CIRP 2013, 12, 438-443. [CrossRef]

24. Behunova, A.; Soltysova, Z.; Behun, M. Complexity Management and Its Impact on Economy. TEM J. 2018, 7, 324-329.

25. Dima, I.C.; Gabrara, J.; Modrak, V.; Piotr, P.; Popescu, C. Using the expert systems in the operational management of production. In 11th WSEAS International Conference on Mathematics and Computers in Business and Economics (MCBE'10); WSEAS Press: Iasi, Romania, 2010; pp. 307-312.

26. Zhou, Y.M.; Wan, X. Product variety, sourcing complexity, and the bottleneck of coordination. Strateg. Manag. J. 2017, 38, 1569-1587. [CrossRef]

27. ElMaraghy, H.; Schuh, G.; ElMaraghy, W.; Piller, F.; Schönsleben, P.; Tseng, M.; Bernard, A. Product variety management. CIRP Ann. Manuf. Technol. 2013, 62, 629-652. [CrossRef]

28. Tseng, M.M.; Piller, F. The Customer Centric Enterprise. In The Customer Centric Enterprise: Advances in Mass Customization and Personalization; Springer Science \& Business Media: Berlin, Germany, 2011; pp. 3-16.

29. Chu, C.H.; Luh, Y.P.; Li, T.C.; Chen, H. Economical green product design based on simplified computer-aided product structure variation. Comput. Ind. 2009, 60, 485-500. [CrossRef]

30. Mailharro, D. A classification and constraint-based framework for configuration. Artif. Intel. Eng. Des. Anal. Manuf. 1998, 12, 383-397. [CrossRef]

31. Antonelli, D.; Pasquino, N.; Villa, A. Mass-customized production in a SME network. IFIP Int. Fed. Inf. Process. 2007, 246, 79-86.

32. Aldanondo, M.; Vareilles, E.; Djefel, M. Towards an association of product configuration with production planning. Int. J. Mass Cust. 2010, 3, 316-332. [CrossRef]

33. Helo, P.T.; Xu, Q.L.; Kyllonen, S.J.; Jiao, R.J. Integrated vehicle configuration system connecting the domains of mass customization. Comput. Ind. 2010, 61, 44-52. [CrossRef]

34. Paul, P.; Aldanondo, M.; Vareilles, E. Concurrent product configuration and process planning: Some optimization experimental results. Comput. Ind. 2014, 65, 610-621. 
35. Mueller, D.; Graefenstein, J.; Scholz, D.; Henke, M. Complexity-Oriented Evaluation of Production Systems for Online-Switching of Autonomous Control Methods. In Interdisciplinary Conference on Production, Logistics and Traffic 2019; Springer: Cham, Switzerland, 2019; pp. 246-264.

36. Hu, S.J.; Zhu, X.; Wang, H.; Koren, Y. Product variety and manufacturing complexity in assembly systems and supply chains. CIRP Ann. 2008, 57, 45-48. [CrossRef]

37. Trattner, A.L.; Hvam, L.; Herbert-Hansen, Z.N.L.; Raben, C. Product variety, product complexity and manufacturing operational performance: A systematic literature review. In Proceedings of the 24th International Annual EurOMA Conference, Edinburgh, UK, 1-5 July 2017; pp. 1-10.

38. Abdelkafi, N. Variety Induced Complexity in Mass Customization: Concepts and Management; Erich Schmidt Verlag GmbH \& Co KG: Berlin, Germany, 2008; Volume 7, pp. 1-314.

39. He, J. Complexity in Adaptive Systems. In Encyclopedia of Machine Learning; Sammut, C., Webb, G.I., Eds.; Springer: Boston, MA, USA, 2011; pp. 194-198.

40. Blecker, T.; Friedrich, G.; Kaluza, B.; Abdelkafi, N.; Kreutler, G. Information and Management Systems for Product Customization; Springer Science \& Business Media Inc.: New York, NY, USA, 2004; Volume 7.

41. Felfernig, A.; Friedrich, G.E.; Jannach, D. UML as domain specific language for the construction of knowledge-based configuration systems. Int. J. Softw. Eng. Know. Eng. 2000, 10, 449-469. [CrossRef]

42. Suh, N.P. Axiomatic design theory for systems. Res. Eng. Des. 1998, 10, 189-209. [CrossRef]

43. Suh, N.P. Complexity in engineering. CIRP Ann. Manuf. Technol. 2005, 54, 46-63. [CrossRef]

44. Online Calculator. Available online: http://web.tuke.sk/fvt-mms/complexity/calc.php (accessed on 1 September 2019).

(C) 2020 by the authors. Licensee MDPI, Basel, Switzerland. This article is an open access article distributed under the terms and conditions of the Creative Commons Attribution (CC BY) license (http://creativecommons.org/licenses/by/4.0/). 